\title{
The long game: Five years of simulating the Middle East
}

\author{
Mat Hardy and Sally Totman \\ Deakin University
}

\begin{abstract}
Scholarly literature attesting to the benefits of role play in teaching international relations or political science subjects is abundant and universally positive. However, despite many case studies presenting snapshots of single examples, long term data concerning a role play exercise is difficult to find. This study presents student feedback data gathered from 10 iterations of the Middle East politics simulation carried out over 5 years from 2011-15. The data obtained from over 600 respondents establishes very clear trends in terms of satisfaction, engagement, and workload. The findings demonstrate that students can be significantly engaged in the subject matter through role plays and that they value these opportunities and the learning that ensues, even though it may represent more work than they are used to allotting to traditional assignments. The results show that year after year, successive student cohorts have made a clear judgement that extra work is worthwhile when it pays off against their perceived learning. The inference can also be drawn that they do not see this same pay off when completing essay type assignments.
\end{abstract}

\section{Introduction}

Scholarly literature attesting to the benefits of role play in teaching international relations (IR) and political science (PS) subjects is abundant and universally positive (Asal, 2005; Banks, Groom, \& Oppenheim, 1968; Boyer, Trumbore, \& Frick, 2006; Chasek, 2005; Dougherty, 2003; Hintjens, 2008; McCarthy \& Anderson, 2000; Sasley, 2010; Simpson \& Kaussler, 2009). Grounded in constructivist approaches that favour rich experiential learning opportunities, the literature surrounding role play in teaching IR and PS is so overwhelmingly positive when describing learning outcomes (Wheeler, 2006) that it is difficult to find counter-examples of failed or unsatisfactory experiences in this discipline area. Increased depth and breadth of subject understanding, improved negotiation and collaboration skills, increased empathy and overall improvement of grades are all purported benefits of using role plays in delivering IR and PS subjects. With that underpinning of experiential learning theory, the use of role play to provide politics students with authentic experiences is another purported benefit (Levy \& Orr, 2014).

Central to the use of simulations in education is the concept of engagement (Gleek, 2015). Constructivist theory argues that by being engaged in a task, students can take ownership of their learning, undertake higher order thinking and generate a connectedness to the world beyond the classroom (Newmann \& Wehlage, 1993). Such outcomes are vital in IR and PS, since the complexities and abstractions of the systems and theories studied are often difficult to comprehend without some form of breakthrough intellectual leap on the part of the student. For this reason, examining levels of student engagement in learning tasks within the discipline is of great interest.

In comparison to more descriptive literature surrounding simulations in IR and PS, there are fewer empirical studies of student perceptions of these tasks and the value they place upon them in their learning. As noted by Giovanello, Kirk, and Kromer (2013; p. 198), when considering the use of role plays in the delivery of IR/PS subjects:

The conventional wisdom may reflect reasonable hypotheses and inferences, but evidencebased pedagogy requires the collection and analysis of relevant data. The relative lack of student evaluation evidence is a problematic lacuna in the literature, especially considering the attention paid to undergraduate perceptions of other aspects of learning (e.g., teaching evaluations).

Studies of student experience and outcomes with IR and PS role plays are certainly available (Baylouny, 2009; Biziouras, 2013; Dougherty, 2003; Giovanello et al., 2013; Raymond \& Sorensen, 2007; Stover, 2005; Wakelee \& Itkonen, 2013). This may include generalised discussion of learning outcomes and some presentation of data surrounding student satisfaction, grade scores or other feedback (Blum \& Scherer, 2007; Raymond, 2010; Stover, 2005). Raymond (2012) is critical of the sort of anecdotal evidence 
presented in this corpus of literature, questioning the accuracy of such self-assessment, though again the general trend across all of these studies is positive in terms of reported outcomes. However, the common pattern in these studies is the description and/or measurement of a single occurrence of a simulation or else its presentation as a general exemplar. This may be because the simulation only ran a single time or data was only gathered once. In some studies there may be a comparison between student groups with and without simulation participation, or a before and after contrast. Research that describes the long-term evolution, student response and outcomes of a simulation in the field of IR and PS is largely absent.

This raises questions regarding consistent data on the value of role plays in the IR and PS discipline and how students react to them. Single sets of data can, together, build the case that role plays in these subjects work well. However, the variations among all these examples, their methodologies and the usually one-off nature of the studies make it difficult to construct any sort of baseline on student attitudes and engagement. It is, for example, difficult to control for external variables in a single simulation study run with a small sample size. Was the student experience (positive or negative) mainly due to the simulation itself or because of some other factor pertaining to workload, season, cohort make-up and so on? Moreover, whilst discipline specific knowledge might be gained from a role play (and measured in exam outcomes), the modern higher education market demands more than this. Pressure on academics to deliver broader graduate attribute skill sets places renewed importance on examining simulations as a potential avenue for building such talents. Analysing these outcomes of simulations is also important.

As a means of filling these gaps, a study of the Middle East politics simulation (MEPS) offers this longer term view. The MEPS has been running twice yearly since 1994. An online political role playing platform that replicates diplomatic interaction via email, it has, over 20 years, involved several universities and has been passed on from one teaching generation (and institution) to another. Each instance of the MEPS has seen anywhere from 80-200 students take on 60-100 roles of various state and non-state actors concerned with the Middle East. The role play lasts between 2 and 3 weeks (the duration has changed over the years depending on need) and runs 24/7. Several thousands of students in Australia and the USA would have taken part in the MEPS over its lifetime. As an example of a complex online role play, the MEPS has also been the subject of repeated scholarly investigation (Dracup, 2009; Hardy \& Totman, 2011, 2012, 2013; Ip \& Linser, 2001; Russell \& Shepherd, 2010; Vincent \& Shepherd, 1998; Wills, Leigh, \& Ip, 2010).

Added to this longevity is the stability of the MEPS platform over the decades. For the first 19 years of its use, the MEPS used the same software, unchanged except for tweaks and patches. At the start of 2014, the software was finally upgraded, providing greater compatibility with modern browsers and mobile devices, as well as some additional communication features. In all other regards though, the new system was essentially the same. This constancy makes the MEPS an ideal subject for a longitudinal study of teacher and student experience with a political simulation.

\section{The MEPS in brief}

The MEPS is run as an assignment option in three of the four core undergraduate Middle East studies units at Deakin University. It operates through an HTML interface accessible only via log-in. The interface is an email emulator that mimics the basic functionality of electronic communication, including chat room and faux Twitter functions. The basis of the exercise involves students adopting a role and communicating with each other in that persona, either in planning their own actions or reacting to those of others. There is no finite goal within the exercise (e.g., winning territory or coming up with a specific treaty wording). The intended learning outcomes are for students to gain a deeper understanding of the Middle East political environment (including a respect for the use, misuse, and limitations of violence as a political tool), as well as increasing their skills in communication and self-directed research. Time management, handling competing demands, and team skills are also products of this exercise.

The MEPS represents $60 \%$ of the students' total marks for the trimester (the other $40 \%$ coming from a final exam). These 60 percentile points are derived from a combination of individual (10 marks) and team work (50 marks). Portions of these total marks accrue from several sub-tasks and marking criteria as described in Table 1. 
Table 1

MEPS task breakdown

\begin{tabular}{|c|c|c|c|c|}
\hline Task & When & Objective & Criteria & Grade value \\
\hline $\begin{array}{l}\text { Role profile } \\
\text { (individual) }\end{array}$ & Before start & $\begin{array}{l}\text { Role adoption and } \\
\text { understanding }\end{array}$ & $\begin{array}{l}\text { Demonstrated } \\
\text { understanding of } \\
\text { the role and its } \\
\text { motivations }\end{array}$ & $\begin{array}{l}\text { 10\% (of overall } \\
\text { trimester mark) }\end{array}$ \\
\hline \multirow[t]{2}{*}{$\begin{array}{l}\text { Role play } \\
\text { (team) }\end{array}$} & \multirow[t]{2}{*}{ During } & \multirow{2}{*}{$\begin{array}{l}\text { Role immersion, } \\
\text { improved } \\
\text { understanding, } \\
\text { empathy, } \\
\text { communication and } \\
\text { collaboration skills }\end{array}$} & $\begin{array}{l}\text { Quality (trueness } \\
\text { to life of } \\
\text { communications } \\
\text { and actions) }\end{array}$ & $\begin{array}{l}70 \% \text { of the } 50 \text { marks } \\
\text { for the assignment, i.e., } \\
35 / 50 \text {. }\end{array}$ \\
\hline & & & $\begin{array}{l}\text { Quantity of } \\
\text { communication }\end{array}$ & $\begin{array}{l}10 \% \text { of the } 50 \text { marks } \\
\text { for the assignment, i.e., } \\
5 / 50 \text {. }\end{array}$ \\
\hline $\begin{array}{l}\text { Position paper } \\
\text { (team) }\end{array}$ & End & $\begin{array}{l}\text { Summarising the } \\
\text { role's position on } \\
\text { events that have } \\
\text { occurred in the } \\
\text { simulation }\end{array}$ & $\begin{array}{l}\text { Demonstrated } \\
\text { understanding of } \\
\text { the role and its } \\
\text { motivations }\end{array}$ & $\begin{array}{l}\text { On campus students: } \\
10 \% \text { of the } 50 \text { marks } \\
\text { for the assignment, i.e., } \\
5 / 50 \text {. } \\
\text { Off campus students: } \\
20 \% \text { of the } 50 \text { marks } \\
\text { for the assignment, i.e., } \\
10 / 50 \text {. }\end{array}$ \\
\hline $\begin{array}{l}\text { Live role play } \\
\text { conference } \\
\text { (team) }\end{array}$ & End & $\begin{array}{l}\text { Presenting the role's } \\
\text { position in a } \\
\text { debate/summit }\end{array}$ & $\begin{array}{l}\text { Trueness to life, } \\
\text { ability to present } \\
\text { and rebut points } \\
\text { of importance }\end{array}$ & $\begin{array}{l}\text { On campus students } \\
\text { only: } 10 \% \text { of the } 50 \\
\text { marks for the } \\
\text { assignment, i.e., } 5 / 50 \text {. }\end{array}$ \\
\hline Debrief & $\begin{array}{l}\text { Following } \\
\text { closure of } \\
\text { exercise }\end{array}$ & $\begin{array}{l}\text { Discussing events, } \\
\text { sharing viewpoints } \\
\text { and facilitating } \\
\text { understanding }\end{array}$ & & $\begin{array}{l}\text { Not graded (informal } \\
\text { class discussions) }\end{array}$ \\
\hline
\end{tabular}

The initial assignment is submitted and graded individually and involves a role profile outlining the character or organisation (and their aims and motives) that the student is playing. This early research task helps the student with role identification and understanding the sort of behaviour that would be inherent to their character.

During the 2 weeks that the MEPS runs the teams are graded collectively according to a number of criteria. The main contributing score is known as "Quality" and is a judgement on how true to the real life character the team stays in terms of how they communicate and what actions they undertake. For example, if the Israeli PM decided to give away control of all of the West Bank, this would be deemed as out of character and result in a lower score. There are also smaller mark allocations for the quantity of communication a team sends and their preparation for and performance at a live conference that occurs at the end of the simulation. The portions of these team-based marks varies to take into account on- and off-campus enrolment modes (see Table 1).

A list of roles is made available, and students choose one based upon their preferences and experience, and with some guidance from the convenors. The roles are played by teams of 2, with the occasional exception of very large roles, such as the US President (sometimes 3 players) and the media (3-10 players). Roles might include:

- $\quad$ Political leaders from the Middle East and beyond (e.g., The King of Saudi Arabia, the Prime Minister of Israel, the President of the United States);

- Office bearers of non-government organisations concerned with the Middle East (e.g., United Nations Secretary General, Head of Amnesty International);

- $\quad$ Non-state actors (e.g., Islamic State, Free Syrian Army);

- Cabinet members of significant nations (e.g., Israeli Minister of Defence, Syrian Foreign Minister); 
- $\quad$ Intelligence agencies (e.g., CIA, Mossad);

- Media organisations (For one MEPS each year, all the media teams are played by final year journalism students from Charles Sturt University [CSU]. In the other run for that year, the media teams will be Deakin Middle East Studies students.)

The simulation begins with a scenario written by the convenors that offers a set of imaginary news events. Teams then have to react to these occurrences through in-character communication. For example, a terrorist team may claim responsibility for an attack, a government may plan steps to retaliate for that same attack, an NGO may issue a press release condemning it, an affiliated group may issue a press release applauding it, and so on. From this point on it is up to the teams to generate their own (appropriately researched) actions, in consultation with the convenors. Amongst the dozens of teams playing within the MEPS, the simulation soon proceeds organically, with complex plot lines and interactions occurring.

It should be noted that in the Middle East studies units in which the MEPS runs, it is one of two assignment options. Students may choose the simulation or a more traditional, sole-authored assignment for the same total percentage of their overall grade. They may make that choice in each of those three core units they will complete as part of their major. This means that students can participate in up to three iterations of the exercise.

\section{The survey}

Feedback from participating students has been gathered on the 10 runs of the MEPS that have occurred since the start of 2011 (each example is denoted as T [trimester] 1 or 2 and by year in the data below). The intention of the survey program was twofold: to measure how students were reacting and engaging with the MEPS as a learning tool and also request specific technical feedback on how the software and game mechanics might be improved. The data was gathered via an anonymous and voluntary questionnaire consisting of a mixture of closed questions (including rating scales and simple yes/no/undecided options) and open-ended comment fields (see Appendix A). The questions required input on student satisfaction, their level of activity during the MEPS, comparisons with other learning tasks and their views upon some specific aspects of the software. Open-ended sections sought positive and negative feedback, suggestions, and general observations.

The questionnaire was provided to all participating students on the final day of the simulation and filled (by those who chose to do so) whilst waiting for the live conference role play. At this point the students are almost at the end of their 2 weeks' of work but will not have received any aspect of their score for the assignment. Until the first half of 2013 this was a hard copy questionnaire filled out by hand. After that point, the survey was carried out online and the URL made available to students at the conference and via the MEPS interface.

The limitations of the survey method are largely a product of the manner that the questionnaire was distributed. Until the online surveying commenced, it was only students attending the final conference who would have had the opportunity to complete the questionnaire. This would preclude specific groups of students who were not required to be at the conference:

- $\quad$ students enrolled at one of the university's remote campuses;

- $\quad$ students enrolled in off-campus (distance) education mode;

- $\quad$ individual students electing not to attend the conference, since only one member from each role team need be present to satisfy the task (though all team members may attend if they wish);

- $\quad$ students not from Deakin University (during the course of this data collection, journalism students from CSU participated in the MEPS, usually once a year in T1);

- $\quad$ students not sufficiently motivated or willing to fill out the voluntary questionnaire.

Representation of these groups (bar the last) would likely have increased once the online survey format was made available. 
A further group of students unlikely to be represented in the survey are those who did not complete the MEPS. In each run, around four or five students tend to drop out of the exercise or fail to begin it at all after initially signing up. That their level of satisfaction might be lower is acknowledged.

\section{Results and Discussion}

Over the 5 year period covered by the survey nearly 1,000 Deakin students have participated in at least one MEPS (see Table 2). More than half of this total completed a survey pertaining to each specific run of the MEPS they undertook. Such an accumulation of feedback makes this survey potentially the largest and longest-running set of data on a single political role playing exercise, and perhaps even across any discipline area. Certainly the data set is sufficient in sample size and duration to indicate trends with some certainty and reveal any temporary fluctuations on feedback data. Some of these variations are discussed below.

Table 2

Participation and response rates

\begin{tabular}{|c|c|c|c|}
\hline Sim date & $\begin{array}{l}\text { Total MEPS } \\
\text { Participants* }\end{array}$ & Responses & Response rate \\
\hline T1 2011 & 80 & 58 & $73 \%$ \\
\hline T2 2011 & 83 & 41 & $49 \%$ \\
\hline T1 2012 & 106 & 75 & $70 \%$ \\
\hline T2 2012 & 100 & 49 & $49 \%$ \\
\hline T1 2013 & 84 & 55 & $65 \%$ \\
\hline T2 2013 & 129 & 72 & $56 \%$ \\
\hline T1 2014 & 105 & 61 & $58 \%$ \\
\hline T2 2014 & 145 & 81 & $56 \%$ \\
\hline T1 2015 & 115 & 61 & $53 \%$ \\
\hline T2 2015 & 151 & 56 & $37 \%$ \\
\hline Total & $\mathbf{1 0 9 8}$ & $\mathbf{6 0 9}$ & $\mathbf{5 5 \%}$ \\
\hline
\end{tabular}

Note. *not including CSU students

Responses to the survey questions were tallied in spreadsheets. In the case of the 5-point rating scale questions presented below, it was common that the results were unipolar, with most responses clustered at one end, either none or a handful at the opposite, and generally none in the middle. For reasons of visual simplicity then, the data presented below tends to depict end of the scale where most respondents sat, though indications of the rarer opposite feedback are provided in the accompanying text. The open-ended responses are not presented in this article, except where a few comments are included to indicate general sentiment. Likewise the data pertaining to the specific software and suggestions for technical changes does not fall within the scope of this paper. The focus instead is on those questions dealing with student engagement, learning outcomes, and workload.

\section{Satisfaction data}

The question of how the MEPS rates as a learning experience asks students to select from a 5-point rating scale (excellent, good, average, poor, very poor). As shown in Figure 1 the majority of respondents (sometimes all) indicate that they found the exercise an excellent or good learning experience. The lowest level in this regard is still close to $90 \%$. Across the 5 years only 13 respondents out of 609 have rated the MEPS as a poor or very poor as a learning experience. 


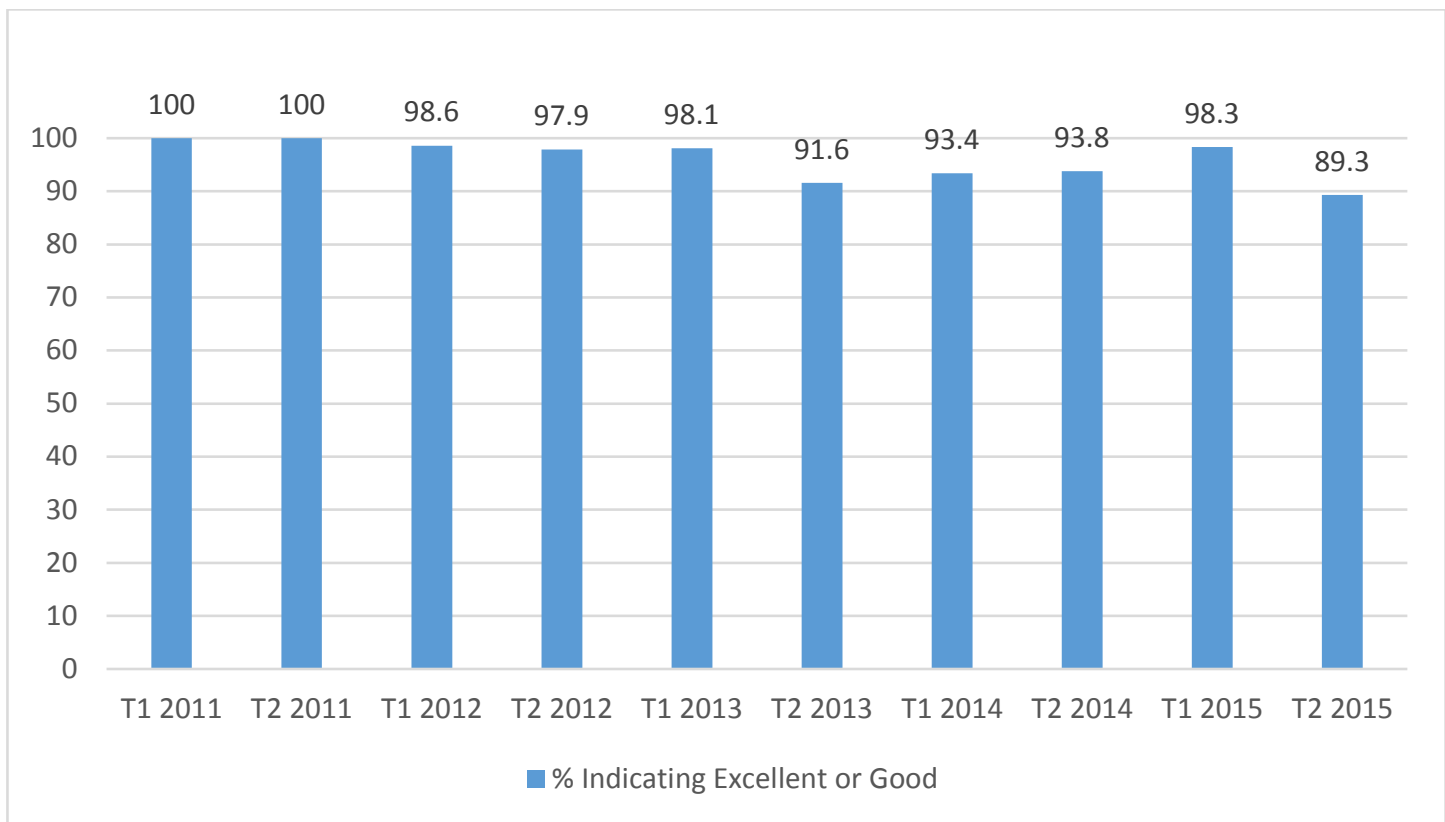

Figure 1. Responses to "How does the MEPS rate as a learning experience?"

Such a high level of reported satisfaction is very supportive of the MEPS as a learning tool. Whilst criticism might sometimes be made that students are not necessarily in a position to judge their own learning outcomes (or that what is learnt may not be relevant to the course), the longitudinal data spread indicates the continually high value that MEPS students place upon the exercise. This is an important lesson for those considering the use of a role play exercise in any discipline.

The high appraisal of the MEPS as a learning experience is reinforced by the responses to another 5-point scale in the questionnaire that asks students to compare the simulation as a learning experience with traditional assignments they have experienced at university, such as essays (much better/better/the same/worse/a lot worse). As shown in Figure 2, the rankings here are similarly high, with all but one MEPS ranking beyond the $90 \%$ rate in terms of respondents indicating much better or better. The average across the years is $94.12 \%$ in this regard.

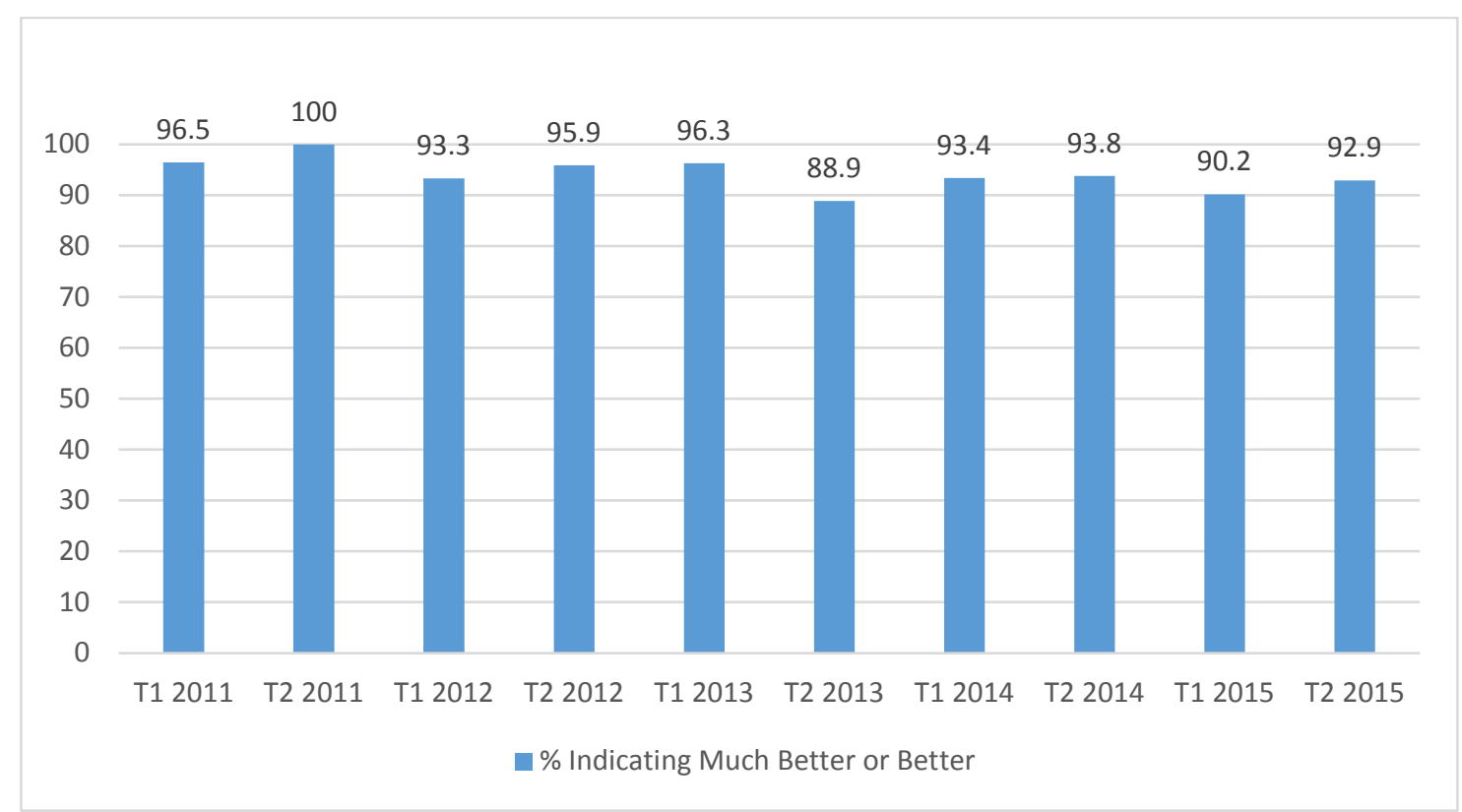

Figure 2. Responses to "How does the MEPS compare to traditional assignments?" 
In the questionnaire's open response box asking students what they liked about the MEPS, comparison with traditional assignments was often noted. Representative comments on this included:

- $\quad$ Beats the hell out of boring essay.

- I liked the hands on approach to learning, rather than just research and writing an essay. You get to understand the tensions and difficulties of the region a lot better when you are trying to replicate it rather than just writing an essay on the difficulties of Israeli-Palestinian negotiations.

- I much prefer a medium intensity, sustained piece of work like the Sim to a traditional essay that requires short period of intense work.

- It was a different learning experience and I found it more engaging and interesting than a boring essay. I learn way more.

- I really do value and enjoy the learning experience ... overall I get more out of a sim than I do from most essays.

\section{Workload and return on investment}

Noting this highly positive reception of the MEPS with traditional assignments may lead to the inference that the MEPS is somehow a short-cut to a good grade or less work than an essay. However, this is not borne out in the questionnaire, since there is a strong indication that students spend vastly more time and effort on this assignment than on other tasks. From T2 2012 onwards students were asked to nominate how long per day they spent on the MEPS, including time researching, intra-team communications and writing and responding to in-game emails. Across the 12 days that the MEPS runs, the average reported time commitment was about 4 1/2 hours per day (see Figure 3). Significantly, a large group of students in each questionnaire reported that their daily time commitment was in the 8 hours-plus category, the maximum time allocation option allowed for in the survey's design. Even allowing for some element of exaggeration in this self-reporting, the overall time that students apparently invest in the MEPS would appear far greater than that which they may apply to a traditional written task.

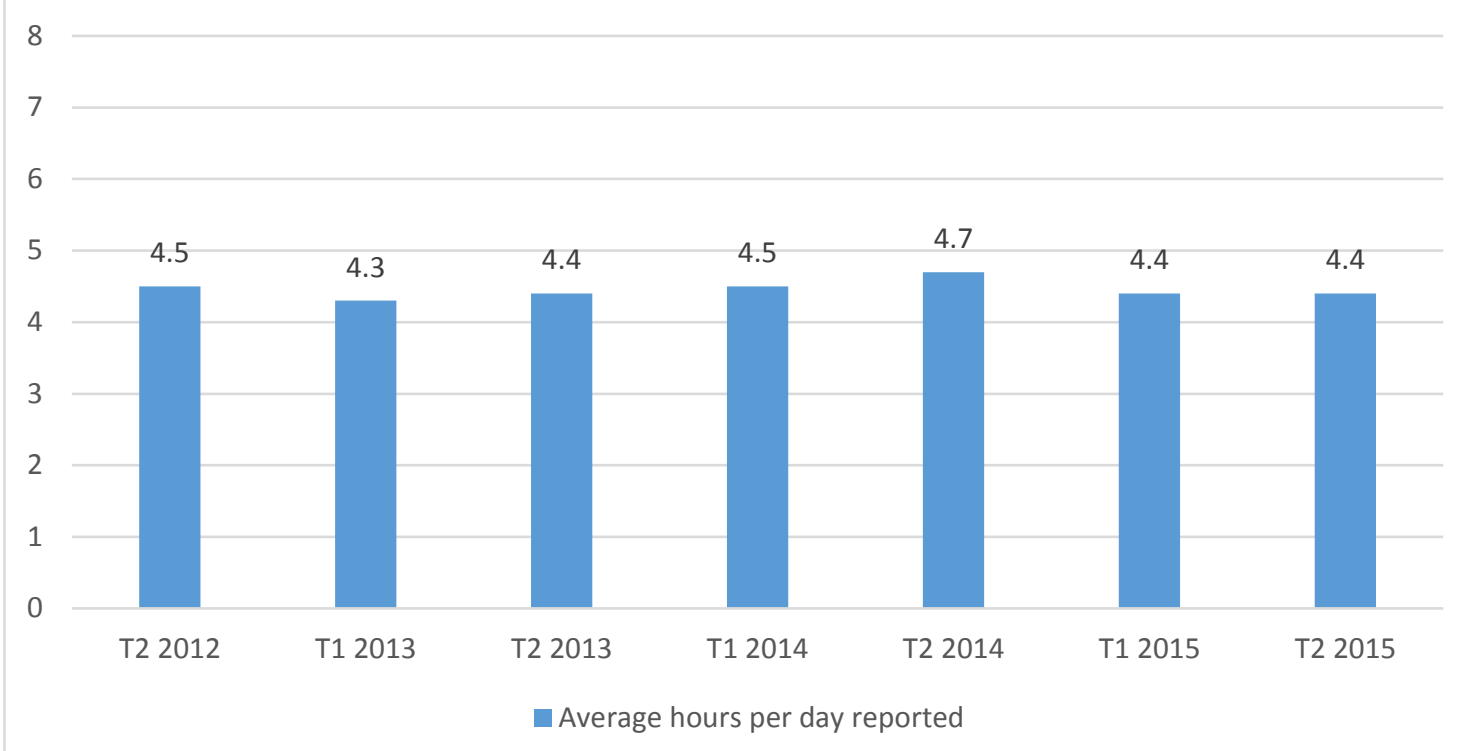

Figure 3. Average hours per day indicated by students they spend on the MEPS

The heavy time commitment is further evidenced in free comment sections of the questionnaire, particularly the question "What didn't you like about the MEPS?":

- It takes over your life!

- I didn't have a life for 2 weeks and became violently obsessed with logging on and writing articles.

- $\quad$ The intensity. It was hard to do other uni work and (paid) work at the same time. 
- I usually found I spent more than 12 hours a day working on the sim, and even when I left I dreamed about the Middle East. It sounds sort of funny but it was actually quite overwhelming and draining at times.

- Definitely dominates your life, all other assignments really had to be put on hold as the Sim is very distracting.

Such quantitative and qualitative responses to the workload inherent in the MEPS indicate that students are not rating their satisfaction with the simulation because it is an easy alternative. Rather, their high approval is expressed despite the excessive workload. Knowledge of the required time commitment is not always post-factual either. In an average T2 example of the MEPS, about one third of the students will have participated in at least one previous simulation. The fact that many students choose to undertake the MEPS three times over the course of their studies, being fully cognisant of the workload after their first run, suggests that they are willing to invest themselves in learning activities that they feel offer a good return.

The perceived return on investment is reinforced by responses to the question of whether the student would recommend the MEPS to their peers (see Figure 4). An average of $91.75 \%$ of respondents across the years answer this question positively. Of the 609 total respondents, only 15 have indicated that they would not recommend the MEPS to a fellow student. A further few percent each time indicate uncertainty over this question. That students are aware of the workload entailed at the point they answer this question points to the fact that they are able to weigh the outcomes they believe ensue and find the equation worthwhile enough to recommend to others.

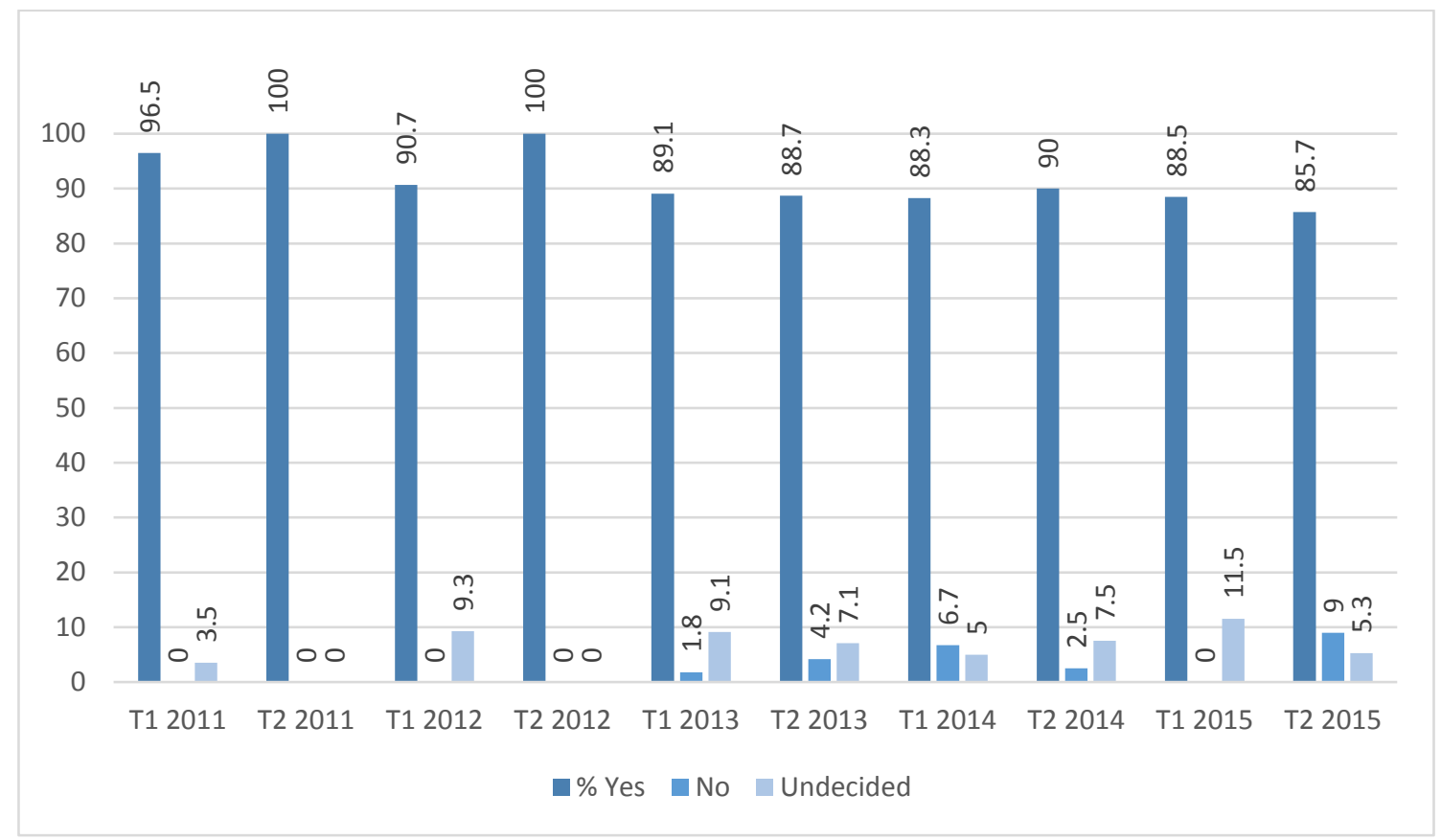

Figure 4. Responses to "I would recommend the MEPS to other students."

A final piece of evidence pointing toward students' willingness to undertake difficult and time consuming role playing tasks is offered by the responses to the question of whether the respondent would like to do another MEPS (see Figure 5). On average over $80 \%$ of survey respondents indicate their desire for a repeat simulation. The open ended comments also included many statements about students looking forward to their next MEPS or lamenting the fact that they would not get to do another. It is to be noted that the ratio of positive to negative responses was significantly different in the T1 2015 MEPS, with a much greater number of students reporting they would not want to do another simulation. The convenors have no explanation for this atypical result since no significant changes had been made to the exercise from the previous two runs and the participant numbers and response rate to the questionnaire were average. Moreover, as seen in Figure 4, not a single respondent from the same survey period indicated that they would be unwilling to recommend the MEPS to a fellow student. Deviating data sets such as this do point to the value of long-term analysis of such exercises, since snapshot data may be extraordinary. 


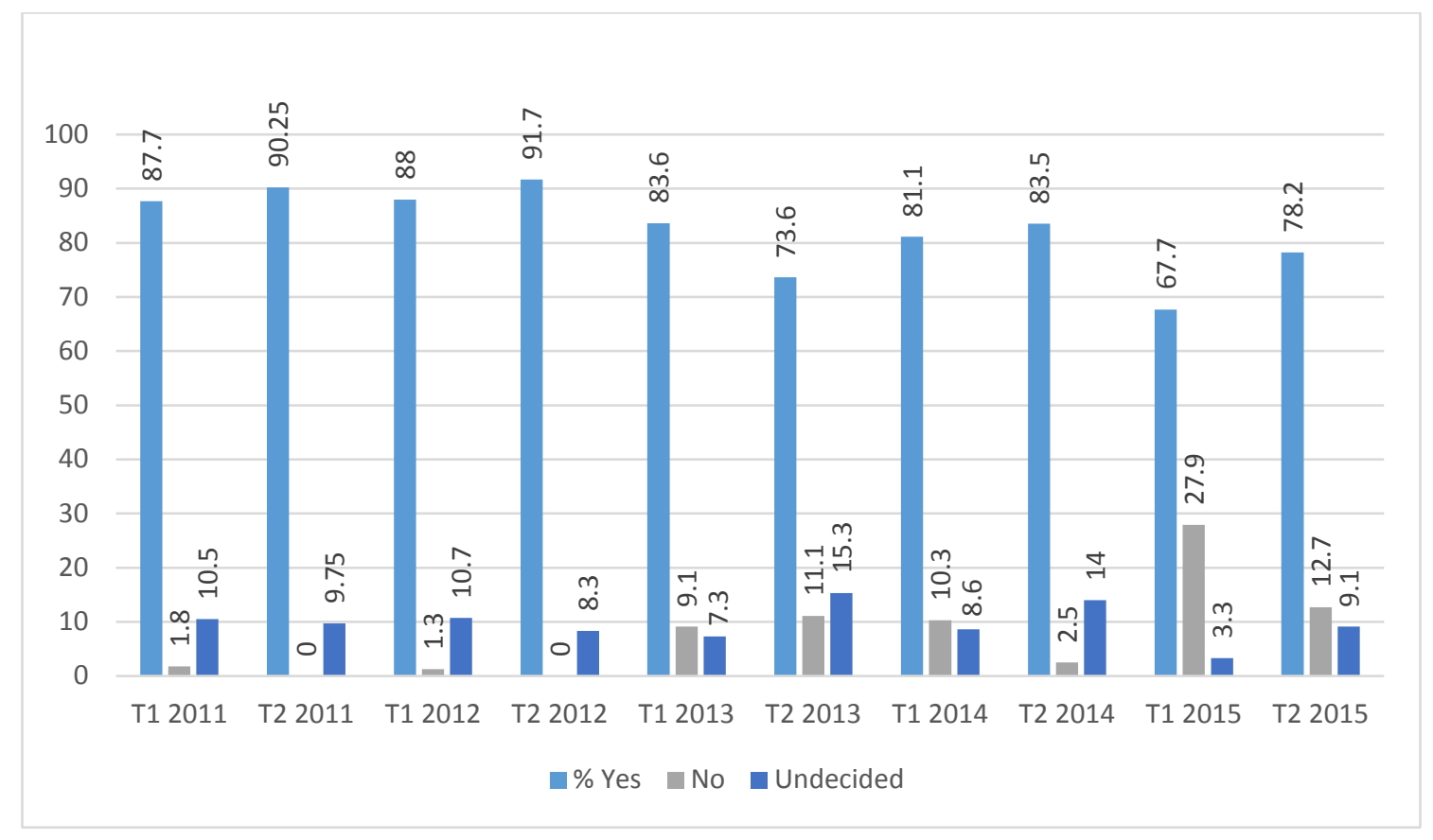

Figure 5. Responses to "I would do another MEPS if I had the chance."

\section{Learning outcomes}

Attempting to measure the learning outcomes of the MEPS is as difficult as it is with any other form of assessment. As noted earlier, the MEPS is one of two assignment options open to students within the Middle East studies units. In the final (essay-based) exam for the unit with the largest enrolment there is no significant difference in performance between those who opt for the simulation and those who chose the written assessment. For example, in T1 2014, those who chose the MEPS scored an average of 22.3/40 for the exam, versus 22.5 for those who did the written assignment. Other trimesters show similar decimal point differences. However, the exams are based on the lecture material from the units, which cover historical and factual recall material linked to disciplinary learning outcomes. Knowledge and understanding from the MEPS or the briefing paper assignment will be equally applicable to the exam, so no real advantage accrues to either assignment group. The effect of simulation participation on exam performance in politics subjects is a difficult one, with some authors finding no significant difference (Krain \& Lantis, 2006; McCarthy \& Anderson, 2000; Raymond, 2010), but others noting an improvement (Frederking, 2005). In any case, the relationship between exam performance and learning is debatable.

However, the survey data indicates that the students themselves feel they have learnt a great deal through the exercise and that it has increased their appetite for and understanding of the topic area. A 5-point rating scale asked "How would you rate your engagement with/awareness of Middle East politics during the Sim?" with possible responses of very high/high/average/low/very low. On average $87.7 \%$ of respondents reported that their engagement was very high or high (see Figure 6). 


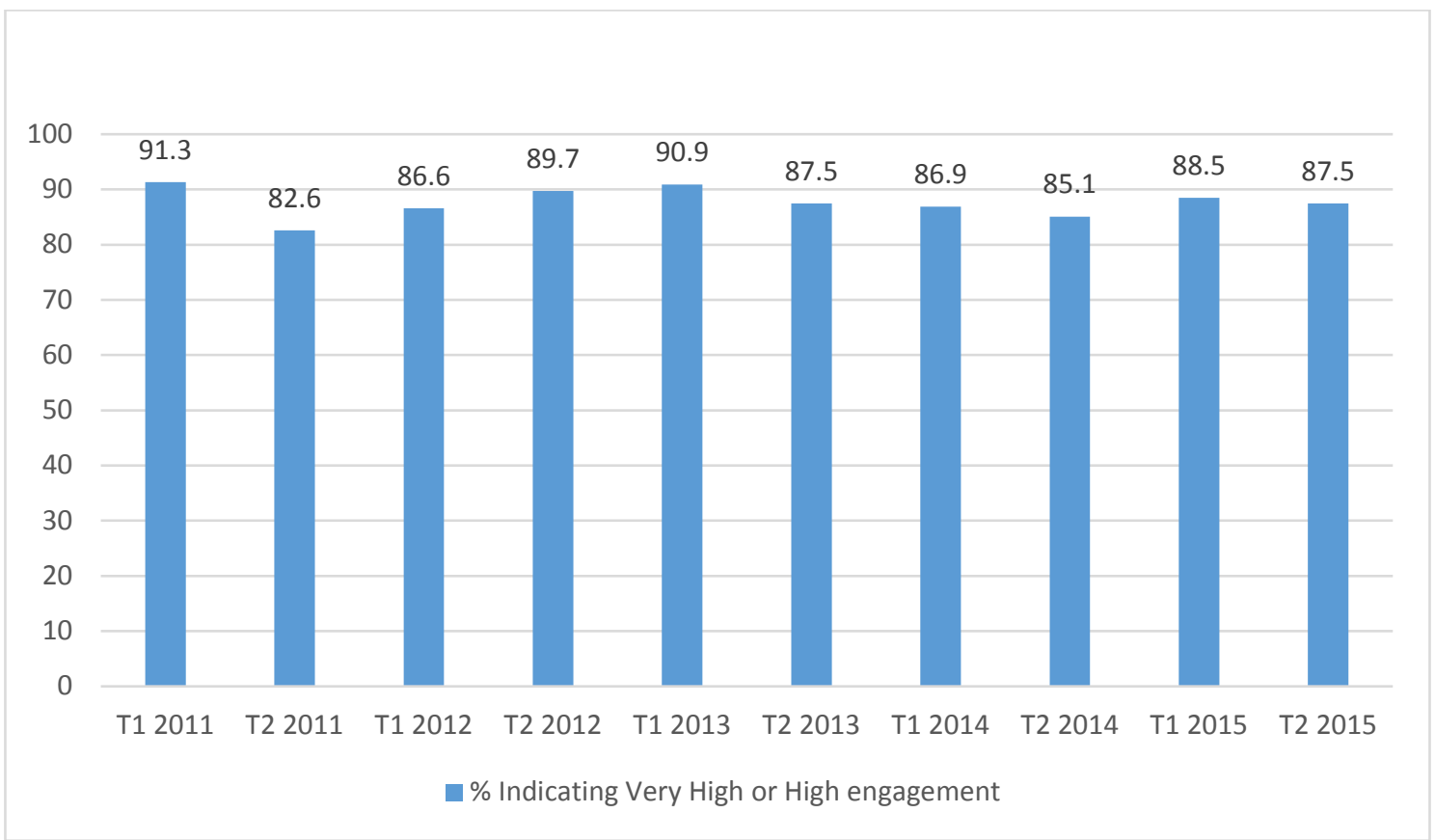

Figure 6. Responses to "How would you rate your engagement with the subject of Middle East politics during the MEPS?"

A further rating scale (1-10 with 10 the most positive) asked to what extent students felt the MEPS had contributed to their understanding of Middle East politics. Over the years of the research this data remained fairly constant, at just over $8 / 10$. Responses to this question of $<6$ were very rare within the data (see Figure 7).

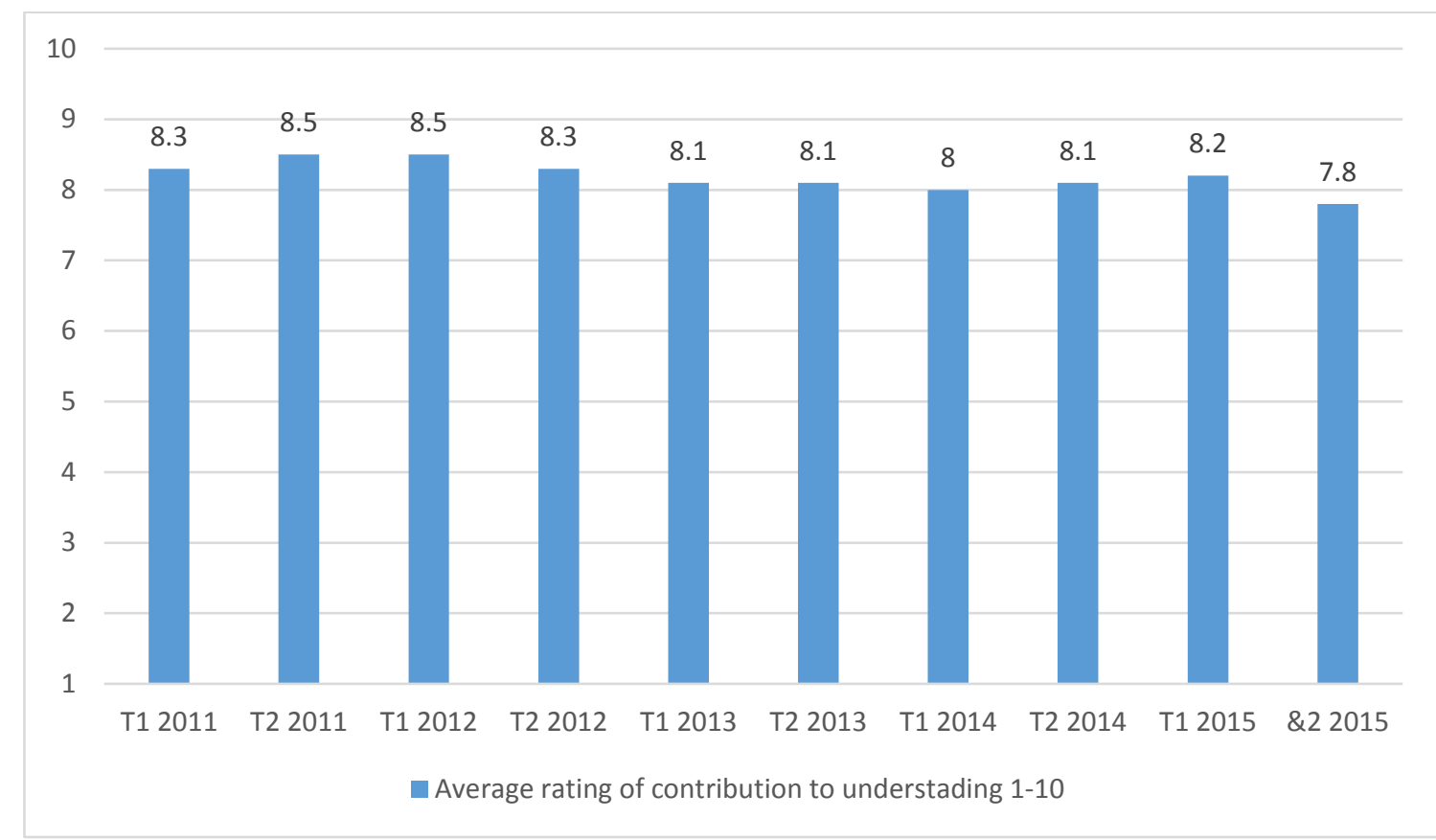

Figure 7. Responses to "How much do you think the MEPS contributed to your understanding of Middle East politics?"

Combined, these two sets of data indicate that students felt highly absorbed in the topic area and that they consider they had gained an improved understanding of the subject. It is difficult not to consider these results as positive learning outcomes, even if they may not be reflected in exam scores. Constructivist ambitions such as connectedness to the outside world would certainly be well supported by this data. 
Additionally, there will be gains in the sort of meta skills that Australian universities are increasingly nominating in their strategic emphasis upon graduate attribute outcomes. For example, at the university where the MEPS runs, the institution's strategic plan aims to offer all graduates:

- discipline-specific knowledge and capabilities

- communication

- digital literacy

- critical thinking

- $\quad$ problem solving

- $\quad$ self-management

- teamwork

- $\quad$ global citizenship

The online structure and objectives of the MEPS would contribute in many or all of these areas. In an openended question that asked students what they felt they had learnt from doing the exercise, all of these outcomes will occur somewhere in the data set for each run. For example, in the TI 2014 responses, many comments revolved around discipline specific discoveries. In addition there were statements such as:

- That you really need to work hard to forge some connections. Also, you're better off responding to everyone to see if they're willing to engage with you further. (communication skills)

- I learned to look at the issues from the character's point of view (global citizenship)

- U.S. intervention in the Middle East is billed as bomb Syria or not bomb Syria, or back the military, or don't back the military. But there are plenty of solutions that are, potentially, far more useful in the long-term. Education, is the biggest form of soft power to shape the openness of Arab world, and it should be leveraging it. (critical thinking)

- I was able to learn through my own research just how extensive the restrictions placed on Gaza are ... also I was able to research the human rights issues cause by occupation, the allocation of blame for said issues, and Israel's abuse of the system (digital literacy, self-management)

- It forced you to research and work on team communication (teamwork)

- You try your hardest to make one state happy but in turn you disgruntle another. (problem solving)

The level of engagement indicated by the data, combined with the outcomes students report for themselves further reinforces role plays as a form of work integrated learning for students of IR and PS; a discipline area where the opportunities for such on the job experience are not always obvious.

\section{Outliers in the data set}

As noted above, the long term measurement of simulation exercises is rare in the literature. Moreover, snapshot surveys of single run simulations pose difficulties in terms of assessing whether the data is representative or anomalous. The value of the MEPS data presented here is that it enables solid trends - and therefore atypical results - to be more easily identified.

The peculiar result noted above for T1 2015 over the question of whether students would want to do another simulation is an example. Given that the data gathered in the other questions for that run of the MEPS is not particularly remarkable or different from the established trends, over-reacting to such a one-time response would be unwise. In any case, this certainly serves as a cautionary tale as to the perils of utilising single data sets when planning or considering role plays as a teaching tool.

By contrast, the data from T2 2013 is worth further analysis as the results across multiple questionnaire sections show lower scores in comparison to established trends. Similarly there is a slight downward trend in the final data set from T2 2015. The reasons for these fluctuations in the reported student experience cannot be conclusively determined. However one indicator may lie in the responses to the question of teamwork and workload sharing for both sessions. The statement "Our team shared the work equally" offered respondents the options of yes/no/undecided (see Figure 8). It is to be noted that the T2 2013 and T2 2015 data is significantly out of correlation with the other sessions and well below the average score of $65.8 \%$ positive. 


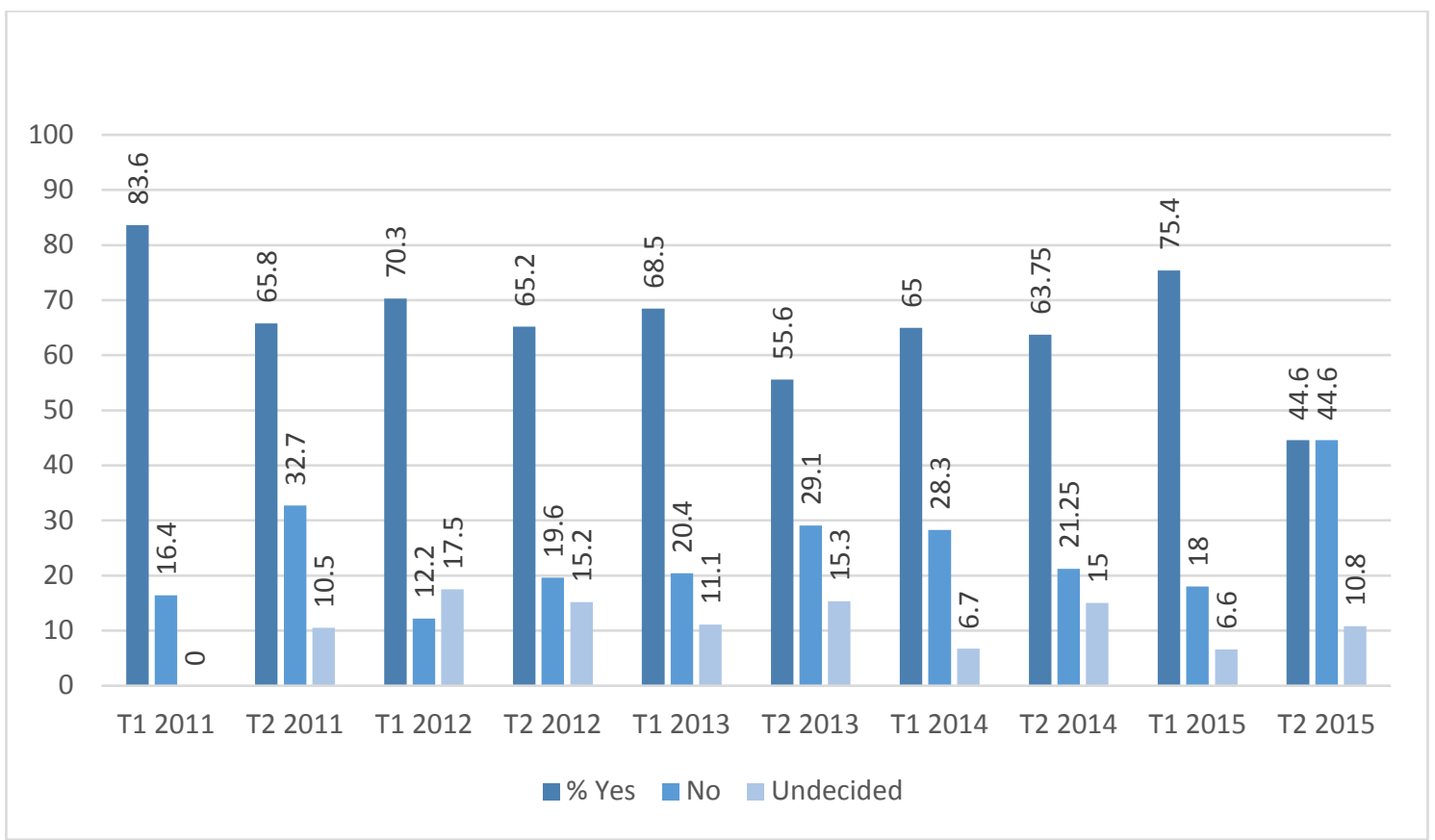

Figure 8. Responses to "Our team shared the work equally."

The issue of workload in group projects is not just a challenge that emerges in online role plays, but for all types of co-operative tasks. Evidence suggests that many students have a dislike for group assignments, with the principle objection being a fear of unequal contribution amongst the group (Aggarwal \& O'Brien, 2008). It is to be noted that differing structures of assessing/grading group versus individual contribution to the overall task can affect the strength of such feelings.

In this latter regard, the MEPS is vulnerable to group dysfunction. With a shared log-in between team members, there is currently no possibility within the software to prove which contributions belong to which student. The final grade is based on the role and both members playing that role receive a score that then goes to make up 50\% of their individual marks for the trimester. In a team of two, one person not pulling their weight (or being perceived to) has a significant impact on the other's experience and their concern over grades. Whilst the MEPS convenors do encourage students to report contribution imbalance so that it can be addressed, it will nevertheless still have repercussions on the aggrieved party's feedback. It is also not uncommon for the dysfunction to occur between two friends who have elected to play the MEPS as a team. In this case, reporting a friend's idleness to the convenors may not be socially acceptable, so the first that is known of it is in the anonymous questionnaire.

If the T2 2013 and 2015 sessions did have a significantly abnormal level of team workload imbalance, this would go a great way to explaining why the range of satisfaction data is generally lower than that recorded for other iterations. Such general dissatisfaction might have also exacerbated the other possible contributing factors.

\section{Conclusion}

Comparisons with other long-term studies of IR and PS role plays are not possible at the moment owing to a lack of similar longitudinal research. Any based on a comparable survey instrument would be valuable if and when they become available, since they may demonstrate similarities or differences in feedback based upon the different mechanisms employed.

However, the existing positive research surrounding the use of role plays in teaching IR and PS is further supported by this long term study of the MEPS. The multiple sets of data obtained from hundreds of respondents establish very clear trends in terms of satisfaction, engagement and workload. These findings follow the larger trend in the literature showing students can be significantly engaged in the subject matter through role plays. According to constructivist theory, this level of engagement has the power to offer the 
transformative leaps of understanding that the IR and PS discipline requires. Moreover, this goal of engagement is now supported by consistent data that demonstrates that students unequivocally value such opportunities and the learning that ensues, even though it may represent significantly more work than they are used to allotting to traditional assignments. The data demonstrates that year after year, successive student cohorts have made a clear judgement that extra work is worthwhile when it pays off against their perceived learning.

The importance of long term studies such as this is evidenced in the outlying data sets where some factor or another was not in correlation with the overall trend. In any simulation it is hard to control for all factors when measuring student response. It is therefore useful to be able to look at the longer term trend as a means of identifying what might have been causing a change in experience.

Finally, whilst there may be occasions where the level of positive feedback drops owing to some factor, the overall rate remains consistently high and indicates the MEPS exercise is valued by participants. Achieving approval ratings beyond $90 \%$ year after year is a rarity in the real-life political world, but in a simulated one the voters seem unfailingly loyal.

\section{References}

Aggarwal, P., \& O'Brien, C. L. (2008). Social Loafing on Group Projects: Structural Antecedents and Effect on Student Satisfaction. Journal of Marketing Education, 30(3), 255-264. https://doi.org/10.1177/0273475308322283

Asal, V. (2005). Playing Games with International Relations. International Studies Perspectives, 6(3), 359-37, 10.1111/j.1528-3577.2005.00213.x

Banks, M. H., Groom, A. J. R., \& Oppenheim, A. N. (1968). Gaming and Simulation in International Relations. Political Studies, 16(1), 1-17. https://doi.org/10.1111/j.1467-9248.1968.tb01440.x

Baylouny, A.-M. (2009). Seeing Other Sides: Nongame Simulations and Alternative Perspectives of Middle East Conflict. Journal of Political Science Education, 5(3), 214-232. https://doi.org/10.1080/15512160903035658

Biziouras, N. (2013). Bureaucratic Politics and Decision Making Under Uncertainty in a National Security Crisis: Assessing the Effects of International Relations Theory and the Learning Impact of Role-Playing Simulation at the U.S. Naval Academy. Journal of Political Science Education, 9(2), 184-196. https://doi.org/10.1080/15512169.2013.770987

Blum, A., \& Scherer, A. (2007). What Creates Engagement? An Analysis of Student Participation in ICONS Simulations. Paper presented at the APSA Teaching and Learning Conference, Charlotte, NC, USA.

Boyer, M. A., Trumbore, E., \& Frick, D. E. (2006). Teaching Theories of International Political Economy from the Pit: A Simple In-Class Simulation. International Studies Perspectives, 7(1), 67-76. https://doi.org/10.1111/j.1528-3577.2006.00231.x

Chasek, P. S. (2005). Power Politics, Diplomacy and Role Playing: Simulating the UN Security Council's Response to Terrorism. International Studies Perspectives, 6(1), 1-19. https://doi.org/10.1111/j.1528-3577.2005.00190.x

Dougherty, B. K. (2003). Byzantine Politics: Using Simulations to Make Sense of the Middle East. PS: Political Science \& Politics, 36(02), 239-244. https://doi.org/10.1017/S1049096503002154

Dracup, M. (2009). Story as a vehicle for learning in online role play: a case study. Paper presented at the AARE International Education Research Conference - 2009, Canberra.

Frederking, B. (2005). Simulations and Student Learning. Journal of Political Science Education, 1(3), 385-393. https://doi.org/10.1080/15512160500261236

Giovanello, S. P., Kirk, J. A., \& Kromer, M. K. (2013). Student Perceptions of a Role-Playing Simulation in an Introductory International Relations Course. Journal of Political Science Education, 9(2), 197-208. https://doi.org/10.1080/15512169.2013.770989

Gleek, C. (2015). Understanding Student Engagement During Simulations in International Baccalaureate Global Politics. I.e.: Inquiry in Education, 7(1), 1-17.

Hardy, M., \& Totman, S. (2011). Should We Teach an Old Game New Tricks? Paper presented at the ASCILITE 2011, Hobart, Australia.

Hardy, M., \& Totman, S. (2012). From Dictatorship to Democracy: Simulating the Politics of the Middle East. In C. Nygaard, N. Courtney, \& E. Leigh (Eds.), Simulations, Games and Role Play in University Education, (pp. 189-206). Faringdon: Libri Publishing. 
Hardy, M., \& Totman, S. (2013). Using an online simulation to address equity issues for off-campus students. In J. Willems, B. Tynan, \& R. James (Eds.), Outlooks and Opportunities in Blended and Distance Learning (pp. 139-153). Hershey, PA: IGI Global. https://doi.org/10.4018/978-14666-4205-8

Hintjens, H. M. (2008). Through the looking glass? Learning from Simulating Rwanda. Paper presented at the World Conference on E-Learning in Corporate, Government, Healthcare, and Higher Education 2008, Las Vegas, Nevada, USA.

Ip, A., \& Linser, R. (2001). Evaluation of a Role-Play Simulation in Political Science. The Technology Source, (January / February 2001). Retrieved from http://technologysource.org/article/evaluation_of_a_roleplay_simulation_in_political_science/

Krain, M., \& Lantis, J. (2006). Building Knowledge? Evaluating the Effectiveness of the Global Problems Summit Simulation. International Studies Perspectives, 7(4), 395-407. https://doi.org/10.1111/j.1528-3585.2006.00261.x

Levy, D., \& Orr, S. (2014). Balancing the Books: Analyzing the Impact of a Federal Budget Deliberative Simulation on Student Learning and Opinion. Journal of Political Science Education, 10(1), 6280. https://doi.org/10.1080/15512169.2013.859084

McCarthy, J. P., \& Anderson, L. (2000). Active Learning Techniques Versus Traditional Teaching Styles: Two Experiments from History and Political Science. Innovative Higher Education, 24(4), 279294. https://doi.org/10.1023/b:ihie.0000047415.48495.05

Newmann, F., \& Wehlage, G. (1993). Five Standards of Authentic Instruction. Educational Leadership, 50(7), 8-12.

Raymond, C. (2010). Do Role-Playing Simulations Generate Measurable and Meaningful Outcomes? A Simulation's Effect on Exam Scores and Teaching Evaluations. International Studies Perspectives, 11(1), 51-60. https://doi.org/10.1111/j.1528-3585.2009.00392.x

Raymond, C. (2012). Missing the Trees for the Forest?: Learning Environments Versus Learning Techniques in Simulations. Journal of Political Science Education, 8(1), 69-84. https://doi.org/10.1080/15512169.2012.641405

Raymond, C., \& Sorensen, K. (2007). The Use of a Middle East Crisis Simulation in an International Relations Course. Paper presented at the APSA Conference on Teaching and Learning in Political Science, Charlotte, NC, USA.

Russell, C., \& Shepherd, J. (2010). Online role-play environments for higher education. British Journal of Educational Technology, 41(6), 992-1002. https://doi.org/10.1111/j.1467-8535.2009.01048.x

Sasley, B. E. (2010). Teaching Students How to Fail: Simulations as Tools of Explanation. International Studies Perspectives, 11(1), 61-74. https://doi.org/10.1111/j.1528-3585.2009.00393.x

Simpson, A. W., \& Kaussler, B. (2009). IR Teaching Reloaded: Using Films and Simulations in the Teaching of International Relations. International Studies Perspectives, 10(4), 413-427. https://doi.org/10.1111/j.1528-3585.2009.00386.x

Stover, W. J. (2005). Teaching and Learning Empathy: An Interactive, Online Diplomatic Simulation of Middle East Conflict. Journal of Political Science Education, 1(2), 207-219. https://doi.org/10.1080/15512160590961801

Vincent, A., \& Shepherd, J. (1998). Experiences in Teaching Middle East Politics via Internet-based Role-Play Simulations. Journal of Interactive Media in Education, 98(11).

Wakelee, D., \& Itkonen, T. (2013). The Politics of School District Budgeting: Using Simulations to Enhance Student Learning. Journal of Political Science Education, 9(2), 236-248. https://doi.org/10.1080/15512169.2013.770995

Wheeler, S. M. (2006). Role-Playing Games and Simulations for International Issues Courses. Journal of Political Science Education, 2(3), 331-347. https://doi.org/10.1080/15512160600840814

Wills, S., Leigh, E., \& Ip, A. (2010). The Power of Role-based e-Learning : Designing and Moderating Online Role Play. New York: Routledge.

Corresponding author: Mat Hardy, matthew.hardy@deakin.edu.au

Australasian Journal of Educational Technology (C) 2017.

Please cite as: Hardy, M., \& Totman, S. (2017). The long game: Five years of simulating the Middle East. Australasian Journal of Educational Technology, 33(4), 38-52. https://doi.org/10.14742/ajet.2696 


\section{Appendix A \\ Questionnaire}

\begin{tabular}{|l|l|}
\hline QUESTION & RESPONSE OPTIONS \\
\hline $\begin{array}{l}\text { 1. How would you rate the Sim as a learning } \\
\text { experience? }\end{array}$ & excellent, good, average, poor, very poor \\
\hline $\begin{array}{l}\text { 2. How would you describe your learning } \\
\text { experience with the Sim compared to traditional } \\
\text { type assignments (eg., essays)? }\end{array}$ & much better, better, same, worse, a lot worse \\
\hline $\begin{array}{l}\text { 3. How would you rate your engagement } \\
\text { with/awareness of Middle East Politics during the } \\
\text { Sim? }\end{array}$ & very high, high, average, low, very low \\
\hline $\begin{array}{l}\text { 4. How much do you think the Sim contributed to } \\
\text { your understanding of Middle East politics? }\end{array}$ & Indicate number (10 = an exceptional amount, 1 Not at all). \\
\hline $\begin{array}{l}\text { 5. How many hours per day do you (personally) } \\
\text { estimate you spent on the Sim? (including } \\
\text { research, writing, discussing with your team } \\
\text { member/s etc.) }\end{array}$ & Indicate an hours amount on a scale from < 1 to \\
\hline $\begin{array}{l}\text { 6. Tell us one (or more) thing you learned about } \\
\text { the Middle East from doing the sim. }\end{array}$ & open ended comment box \\
\hline $\begin{array}{l}\text { 7. The simulation interface (website) was suitable } \\
\text { for the purpose of the exercise. }\end{array}$ & yes/no/undecided \\
\hline 8. The Sim interface needs to be improved. & yes/no/undecided \\
\hline $\begin{array}{l}\text { 9. More social media tools (such as a fake } \\
\text { Facebook) need to be added to the interface. }\end{array}$ & yes/no/undecided \\
\hline $\begin{array}{l}\text { 10. The interface needs to be more visually } \\
\text { attractive. }\end{array}$ & yes/no/undecided \\
\hline $\begin{array}{l}\text { 11. More explanation needs to be given about } \\
\text { how to play }\end{array}$ & yes/no/undecided \\
\hline 12. The interface is easy to use. & yes/no/undecided \\
\hline 13. I would do another Sim if I had the chance & yes/no/undecided \\
\hline 14. I would recommend the Sim to other students. & yes/no/undecided \\
\hline 15. Our team members shared the work equally & yes/no/undecided \\
\hline 16. My overall experience was positive. & yes/no/undecided \\
\hline 18. What did you like about the Sim? & open ended comment box \\
\hline 19. What didn't you like about the Sim? & open ended comment box \\
\hline $\begin{array}{l}\text { 20. What features would you like to see added to } \\
\text { any future version of the sim? (if any) }\end{array}$ & open ended comment box \\
\hline 21. Any other comments? & open ended comment box \\
\hline 22. Is this your first sim? & yes/no \\
\hline
\end{tabular}

